\title{
NITROGEN BALANCE ON RICE DIET ${ }^{1}$
}

\section{By ERNST PESCHEL AND RUTH LOHMANN PESCHEL}

\author{
(From the Department of Medicine, Duke University School of Medicine, Durham, N. C.)
}

(Submitted for publication October 7, 1949; accepted, December 5, 1949)

The nitrogen excretion in the urine of 52 patients with hypertensive vascular disease or nephritis who followed the rice diet for one to 14 days, averaged, according to Kempner (1), $4.83 \mathrm{Gm}$. daily. In 46 patients who followed it for 15 to 30 days, the average was $3.6 \mathrm{Gm}$., in 26 patients on the diet for one to two months, $2.93 \mathrm{Gm}$. and in 32 patients on the diet for a period longer than two months, the average was $2.26 \mathrm{Gm}$. These were all hospital patients.

Schwartz and Merlis (2) determined the nitrogen excretion of five physically healthy persons and of one patient with multiple sclerosis who had followed the rice diet for eight days, and of one patient with severe hypertension who had been on the diet for 90 days. The nitrogen excretion in the urine of these six people after they had been on the diet three to eight days averaged $4.90 \mathrm{Gm}$. daily : $5.15 \mathrm{Gm}$. on the third day, $4.86 \mathrm{Gm}$. on the sixth, and $4.68 \mathrm{Gm}$. on the eighth day. The patient who followed the diet for 90 days had a urinary nitrogen excretion of $3.81 \mathrm{Gm}$. on the 90 th day. The average nitrogen output in the stool after three to eight days was $1.17 \mathrm{Gm}$., after 84 to 90 days 1.49 $\mathrm{Gm}$. The caloric intake in each case was 2289 calories; the nitrogen intake, according to analysis, was $2.63 \mathrm{Gm}$. per day. Schwartz and Merlis found that under these circumstances all their patients were in negative nitrogen balance. The average nitrogen deficit after eight days was $3.22 \mathrm{Gm}$., the nitrogen deficit after 90 days was $2.67 \mathrm{Gm}$. N per day.

Currens and his associates (3) reported on nitrogen balance tests in two hypertensive patients who were on the rice diet. The first patient, during the first week on the diet, showed a negative nitrogen balance of $5 \mathrm{Gm}$. per day; the second, after three months, showed a negative balance of $1 \mathrm{Gm}$. per day.

We have examined the nitrogen balance in 11 patients with hypertensive vascular disease after

1 This work was aided by a grant from the U. S. Public Health Service.
15 to 220 (average 89) days on the rice diet. One patient was examined after a period of 80 days and again after a period of 170 days. Only male subjects were used. Patients who are not able to eat the rice diet, as happens not infrequently in uremia or after cerebral vascular accidents, are not suitable test subjects for this particular problem. Otherwise, the severity of the vascular disease did not play any role in the selection of the patients for the balance test. Ten of the test subjects had been improving on the diet, or at least their disease had not progressed; one patient (test 10 in Table I) had had a fresh myocardial infarction some weeks before the test. None had malignant hypertension.

One patient (test 10 in Table I) was in the hospital during the test, the others were up and around, staying in hotels or private homes but taking their meals at one of two places where the rice diet is prepared under supervision. The patients followed the same diet that they had been on for some weeks. In order to get an unmodified picture of the metabolic state of each patient, individual variations (within the range permitted by the regime) in regard both to diet and to physical activity remained unchanged. This procedure has the theoretical objection that it does not allow continuous observation of food intake and of stool and urine collections. (Check of a complete urine collection by creatinine determination is not reliable. In patients on the rice diet, the excretion of creatinine and total creatine bodies decreases [4].) Additional food intake would influence the result of the balance determination in a negative direction, incomplete stool and urine collections in a positive direction.

These studies were not carried out in a metabolic ward. This nonconventional method of carrying out balance studies seemed practical for the following reasons: 1 . The patients selected for this study were all professional men or business executives. At a considerable financial sacrifice they had moved to Durham for three months to 
find out whether the rice diet would modify their vascular disease. They were interested in their diet and aware of the fact that the outcome of the test was of decisive importance for the further management of the diet. 2. The degree of cooperation during the days preceding and following the test was determined by a study of the urinary excreation of $\mathrm{Na}$ and $\mathrm{Cl}$. On this diet the excretion of $\mathrm{Na}$ and $\mathrm{Cl}$ in the urine drops to very low levels. Any additions to the diet are reflected quickly in increased excretion of these electrolytes. The excretion of $\mathrm{Na}$ and $\mathrm{Cl}$ in these patients before, during, and after the test indicated strict adherence to the diet. 3. All of these patients had been under careful observation before the test, and all were accustomed to eating a fixed diet and collecting their specimens.

\section{TECHNICAL METHODS}

A special technician who was present at every meal and who also collected the specimens, was in charge of each patient. The food for each patient was weighed and an equal amount of the same food or food preparation taken for analysis. Care was taken that non-edible parts such as cores, kernels and fruit skins were weighed and subtracted in both portions. The single items of each meal were combined on a percentage basis. After dilution with an equal amount of $10 \% \mathrm{NaCl}$ solution which served for rinsing purposes and helped to produce a homogeneous suspension, they were thoroughly blended in a Waring blender. In an aliquot portion of the resulting slurry the nitrogen was determined by a semimicro modification of the Kjeldahl method $(5,6)$, using a modification of the Arnold-Gunning mixture $(7,8)$ for digestion and 0.02 Normal hydrochloric acid for titration. All analyses were made at least in duplicate.

Urine nitrogen determinations were made on 24-hour collections started after the first meal of the test period (the bladder having been emptied before the meal) and finished on the morning of the fifth day before breakfast. The urine bottles contained $3 \mathrm{cc}$. of concentrated nitrogenfree sulfuric acid in order to prevent loss of ammonia. The determinations (using the same method as for the food) were done on each 24 -hour collection as soon as it was completed.

The stool collections, starting at midnight after the first day of the test period, were continued through four 24hour periods. The total food intake of these patients as well as the protein intake had been constant for a long time before the test was started. It was therefore unnecessary to use indicators to mark more closely the connection between the food eaten and the respective stool portions. The stools were deposited in weighed cardboard containers which were kept in large thermos jars. Immediately after being deposited, they were surrounded by dry ice, and thawed only for the determinations. They were weighed, diluted with a known quantity of water and thoroughly treated in a Waring blender. An aliquot amount of the slurry was used for the determination which was done with the same method as that employed for food slurries and urine.

An example of the nitrogen content of a 24-hour intake is given in Table II. The values obtained by our determinations on composites of the single meals were similar to the sum of the values calculated for the individual items from the tables of McCance and Widdowson (9). This was true throughout all the tests. The estimation of the nitrogen balance was based only on our own determinations.

\section{RESULTS}

Results and details of the tests are given in Table I. All patients, who were tested in this series, are included.

The result of the 12 tests (11 patients) shows an average positive nitrogen balance of +0.25 $\mathrm{Gm}$. daily. In five patients the balance was negative, in seven positive. The highest negative figure was $0.78 \mathrm{Gm}$. (intake : 1866 calories) ; the highest positive figure was $1.43 \mathrm{Gm}$. (intake: 2475 calories).

The ages of the test subjects ranged from 40 to 66 years. Age was not a significant factor in the results.

The data on weight show no significant weight change in a two-weeks' period before and after the tests. An average weight loss of $5 \mathrm{Kg}$. had occurred during the first 75 days (average) of the treatment.

Patient 9 was on a modified rice, diet of unknown composition for some months before coming under our supervision. In patient 10, "220 days on the rice diet" included one period of two months during which some small additions had been made to the diet. Before the balance test was begun, this patient had again been on the basic rice diet for two months.

The caloric intake varied according to the eating habits of the individual patient. Patient 2 had been asked to restrict the caloric intake during the whole period of treatment, because of marked overweight in the presence of severe coronary disease. Patient 8 had been encouraged to increase the caloric intake. The average intake of the 11 patients during the 12 test periods was 2063 calories, which is close to the figure of 2000 calories frequently quoted from Kempner's papers. A comment on this figure might be made here. Kempner writes: "The rice diet contains in 2000 calories not more than $5 \mathrm{Gm}$. 
MITROCEN BALANCE

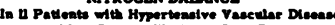

ANer Severel wetto Rece Diet

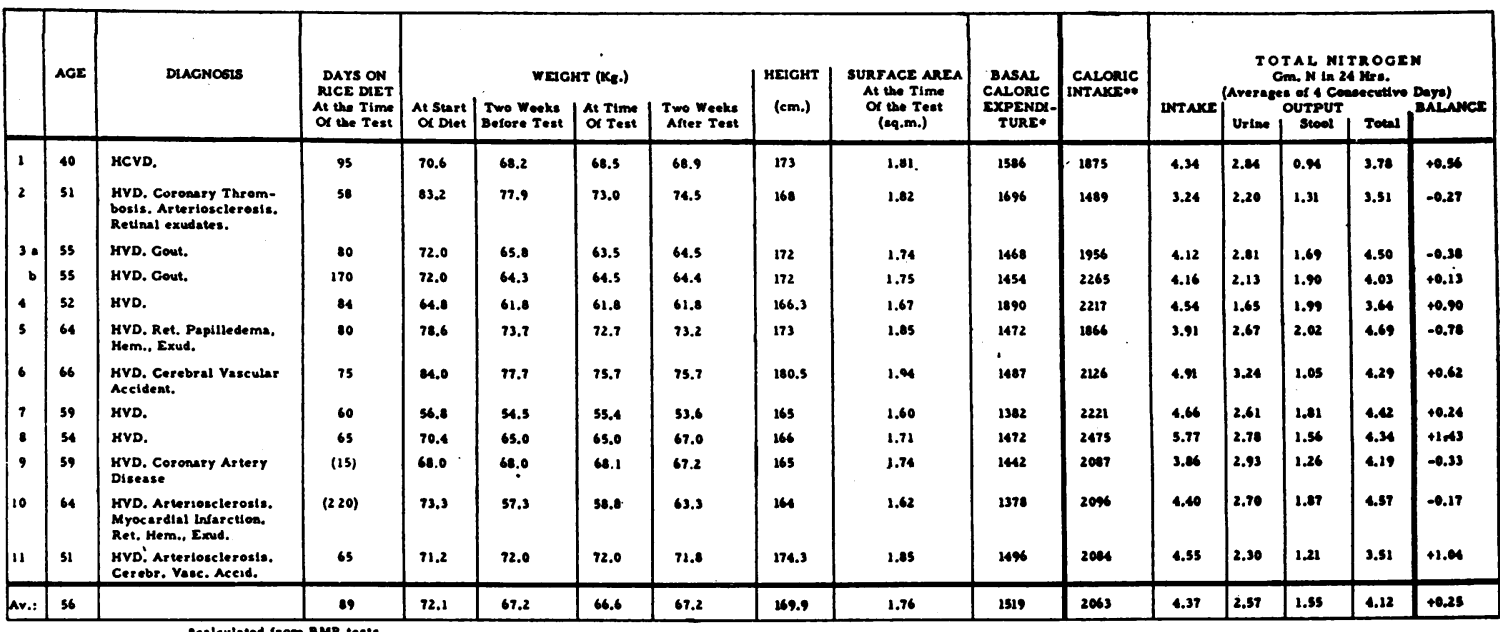

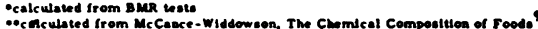

TABLE I

EXAMPLE OF FOOD INTAKE

(Taken From Test Number 3a)

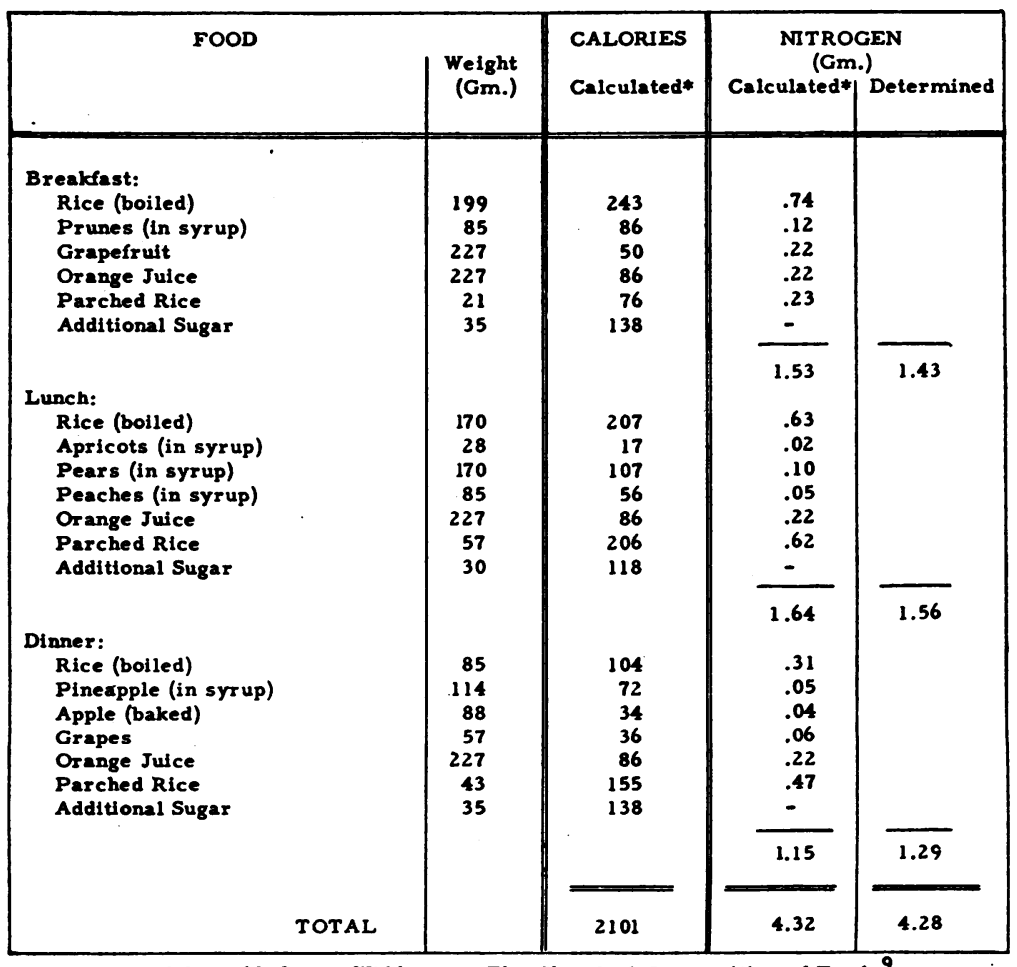

*calculated from McCance-Widdowson, The Chemical Composition of Foods 9 
of fat and about $20 \mathrm{Gm}$. of protein derived from rice and fruit and not more than $200 \mathrm{mg}$. of chloride and $150 \mathrm{mg}$. of sodium." This does not mean that the caloric supply is fixed at 2000 calories. It varies according to the varying indications for weight gain or weight loss in the individual patient. The nitrogen and total caloric intake can be controlled by altering the rice and sugar fractions of the diet.

The total nitrogen intake of the 11 patients averaged $4.37 \mathrm{Gm}$. per day. This represents a protein intake of about $26.4 \mathrm{Gm}$. if one estimates the protein of all foods except rice by multiplying the total nitrogen by 6.25 and that of rice by multiplying the total nitrogen by 5.95 . Since the proteins of cereals contain more nitrogen than is found on the average in other proteins, the nitrogen in the rice protein represents more than the usual $16 \%$ (10).

Urine nitrogen excretion averaged $2.57 \mathrm{Gm}$., stool nitrogen $1.55 \mathrm{Gm}$. per day. The assumption made by some investigators (11) that there may be an additional nitrogen loss through sweat, skin particles or hair, has been questioned (12). We omit this factor, especially since two of our patients had some intestinal irritation during the time of the test (Patients 5 and 10), which means that the stool nitrogen content in these cases was probably slightly higher than it would have been without this disturbance. (In spite of this, in order to avoid any selection, we did not exclude these patients.)

The basal caloric expenditure of the patients was calculated from BMR tests. The BMR was elevated in Patient $4(+29 \%)$, slightly elevated in Patient $2(+5 \%)$; it was slightly decreased in all the others, but did not exceed $-10 \%$, (average in nine patients: $-6 \%$ ).

\section{DISCUSSION}

The nitrogen balance of all 11 patients was close to nitrogen equilibrium on either the positive or the negative side. This may fluctuate slightly in individual patients. But since the test subjects were taken at random and had been on the rice diet for different periods of time when the balance tests were done, it may be assumed that these tests give the usual picture of the nitrogen balance after several weeks on the rice diet.
Until an equilibrium is reached, there is a phase of adaptation with definite negative balances which vary considerably with the individual patient. Approximate figures of this nitrogen loss, based on the average nitrogen excretions of $26-52$ patients reported by Kempner (1), are: for the first 14 days a total of $27 \mathrm{Gm}$., for the next 16 days of $11 \mathrm{Gm}$., for the next 30 days of $1 \mathrm{Gm}$. This would amount to a loss of $39 \mathrm{Gm}$. of nitrogen during the first two months. (There was a positive balance of a total of $10 \mathrm{Gm}$. for the 30 days of the third month which would reduce the total nitrogen loss to $29 \mathrm{Gm}$. if the third month is included.) Thirty-nine Gm. of nitrogen means less than $2.5 \%$ of the total nitrogen content of a $66.6 \mathrm{Kg}$. person.

Negative nitrogen balances of the degree found in our series are probably of minor importance for the period of time during which the strict rice diet is usually necessary. E. Abderhalden determined the nitrogen balance of a physician (13) who lived for four years on a $25 \mathrm{Gm}$. protein diet after having been on a $38-40 \mathrm{Gm}$. protein diet for the previous 15 years. The test subject was feeling well and strong, and during some of the test periods he was extremely active physically (mountain climbing in Switzerland). The balances were close to equilibrium with an average of $-0.07 \mathrm{Gm}$. nitrogen per day in the seven periods of seven to 13 days each. The strenuous exercise did not influence the nitrogen balance.

A negative balance of $-0.39 \mathrm{Gm}$. per day after an average of 91 days on the rice diet- the average of the five negative balance values in our serieswould mean that in 20 days less nitrogen is lost from the body than in one single day of fasting. (According to Benedict [14] the daily nitrogen loss is relatively constant during a fasting period of 31 days, the average being $8.94 \mathrm{Gm}$. per day.)

\section{SUMMARY}

Twelve nitrogen balance tests on 11 patients after an average period of 89 days on the rice diet showed that nitrogen intake and nitrogen output were close to equilibrium in all 12 test periods. Five balances were slightly negative, seven slightly positive. The average of the five negative balances was $-0.39 \mathrm{Gm}$., the average of the seven positive balances $+0.70 \mathrm{Gm}$. per day. The average of the results of all the 12 tests was a positive balance of 
$+0.25 \mathrm{Gm}$. The significance of a slightly negative balance is discussed.

\section{BIBLIOGRAPHY}

1. Kempner, W., Compensation of renal metabolic dysfunction; treatment of kidney disease and hypertensive vascular disease with rice diet; III, Pts. 1 and 2. North Carolina M. J., 1945, 6, 61 and 117.

2. Schwartz, W. B., and Merlis, J. K., Nitrogen balance studies on the Kempner rice diet. J. Clin. Invest., 1948, 27, 406.

3. Currens, W., Reid, E. A. S., MacLachlan, E. A., Terry, M. L., Butler, A. M., and White, P. D., Physiologic, metabolic and electrolytic balance studies of hypertensive patients while on the rice diet. J. Clin. Invest., 1949, 28, 776.

4. Kempner, W., Treatment of hypertensive vascular disease with rice diet. Am. J. Med., 1948, 4, 545.

5. Peters, J. P., and Van Slyke, D. D., Quantitative Clinical Chemistry. Vol. II, Williams and Wilkins, Baltimore, 1932.

6. Bock, J. C., and Benedict, S. R., An examination of the Folin-Farmer method for the colorimetric estimation of nitrogen. J. Biol. Chem., 1915, $20,47$.

7. Arnold, C., and Wedemayer, K., Beitraege zur Stick- stoffbestimmung nach Kjeldahl. Ztschr. f. anal. Chem., 1892, 31, 525.

8. Gunning, J. W., Ueber eine Modification der Kjeldahlmethode. Ztschr. f. anal. Chem., 1889, 28, 188.

9. McCance, R. A., and Widdowson, E. M., The Chemical Composition of Foods. Chem. Pub. Co., New York, 1947.

10. Jones, D. B., U. S. Dept. Agr. Circ. No. 183, 1941, quoted in: Sahyun, M., Proteins and Amino Acids in Nutrition. Reinhold Publishing Co., New York, 1948, p. 136.

11. Bricker, M., Mitchell, H. H., and Kinsman, G. M., The protein requirements of adult human subjects in terms of the protein contained in individual foods and food combinations. J. Nutrition, 1945, 30, 269.

12. Hegsted, D. M., Tsongas, A. G., Abbott, D. B., and Stare, F. J., Protein requirements of adults. J. Lab. \& Clin. Med., 1946, 31, 261.

13. Roese, C., Vierjaehrige Ernachrung an der Grenze des Eiweissmindestbedarfes. Ztschr. f. d. ges. exper. Med. 1934, 94, 579. Also quoted in Strieck, F., Metabolic studies in a man who lived for years on a minimum protein diet. Ann. Int. Med., 1937, 11, 643.

14. Benedict, F. G., A Study of Prolonged Fasting. Carnegie Institution of Washington, Washington, 1915. 